\title{
RESISTANCE TO THE POTATO ROOT EELWORM IN S. TUBEROSUM SUBSP. ANDIGENA AND ITS IMPORTANCE FOR POTATO BREEDING ${ }^{1}{ }^{2}{ }^{2}$ )
}

\author{
C. A. HUIJSMAN \\ Foundation for Agricultural Plant Breeding, Wageningen, Netherlands
}

\section{SUMMARY}

A survey is given of the way in which a search is made for potatoes resistant to the potato root eelworm Heterodera rostochiensis WoLLENWEBER, at the Foundation for Agricultural Plant Breeding, Wageningen. A very high degree of resistance was found in the clone CPC 1673 belonging to the species Solanum tuberosum subsp. andigena. The inheritance of this resistance is dominant and monofactorial. The nature of the resistance is discussed in detail. For the breeding work the method of repeated backcrossing is used. Valuable seedlings were found in the first backcross generation.

Finally a survey is given of the data on the occurrence of biological races of the potato root eelworm which are able to multiply strongly in the resistant material derived from CPC 1673.

\section{INTRODUCTION}

Potato sickness is caused by the cyst-forming nematode Heterodera rostochiensis WoLleNwEBER. The whole life-cycle of this parasite takes place in the soil. If control of soil parasites is in general not easy, that of the potato root eelworm is hampered severely by the eggs being particularly wellprotected by the cyst-wall.

In the Netherlands the spread of the disease is checked by prohibiting the growth of potatoes in infested soil and by the legal regulation that potatoes can be grown at most once in three consecutive years on the same field.

A direct means of control which would be economically justified has not been found as yet. Growing potato varieties resistant to or immune from potato sickness would be the most economical method of control of this disease. This quality of resistance, however, does not occur in the cultivated West European and North American potato varieties (Solanum tuberosum subsp. tuberosum).

A very high degree of resistance has been found in some varieties of Solanum tuberosum subsp. andigena, growing in South Peru and Northern Bolivia. This material has become the basis of an extensive breeding programme, aiming at the creation of potato varieties resistant to potato sickness. The following gives some details of this breeding work.

\section{The SEARCH FOR RESISTANCE AND THE RESULTS OBTAINED}

A potato plant possesses a certain degree of resistance when no cysts are found on the roots (when grown in infested soil) or at any rate so few that the population of the parasite decreases.

1) Received for publication November 28, 1957.

2) Elaborated from the text of a paper read at the Symposium "Plant and Insect" held at Wageningen, The Netherlands, from 28-30 May 1957. 
The procedure for testing the resistance at the Foundation for Agricultural Plant Breeding (Wageningen) is as follows :

The seed is sown in a seed-tray filled with soil which is free from living larvae. When the seedlings are approximately $2 \mathrm{~cm}$ long they are pricked off into another seed-tray. After some time the seedlings are transplanted in pots of $8 \mathrm{~cm}$ diameter. When the seedlings are growing well and the potball is well-rooted, they are ultimately planted into pots of $13-17 \mathrm{~cm}$ diameter, filled with heavily infested soil which has been mixed thoroughly beforehand. Then

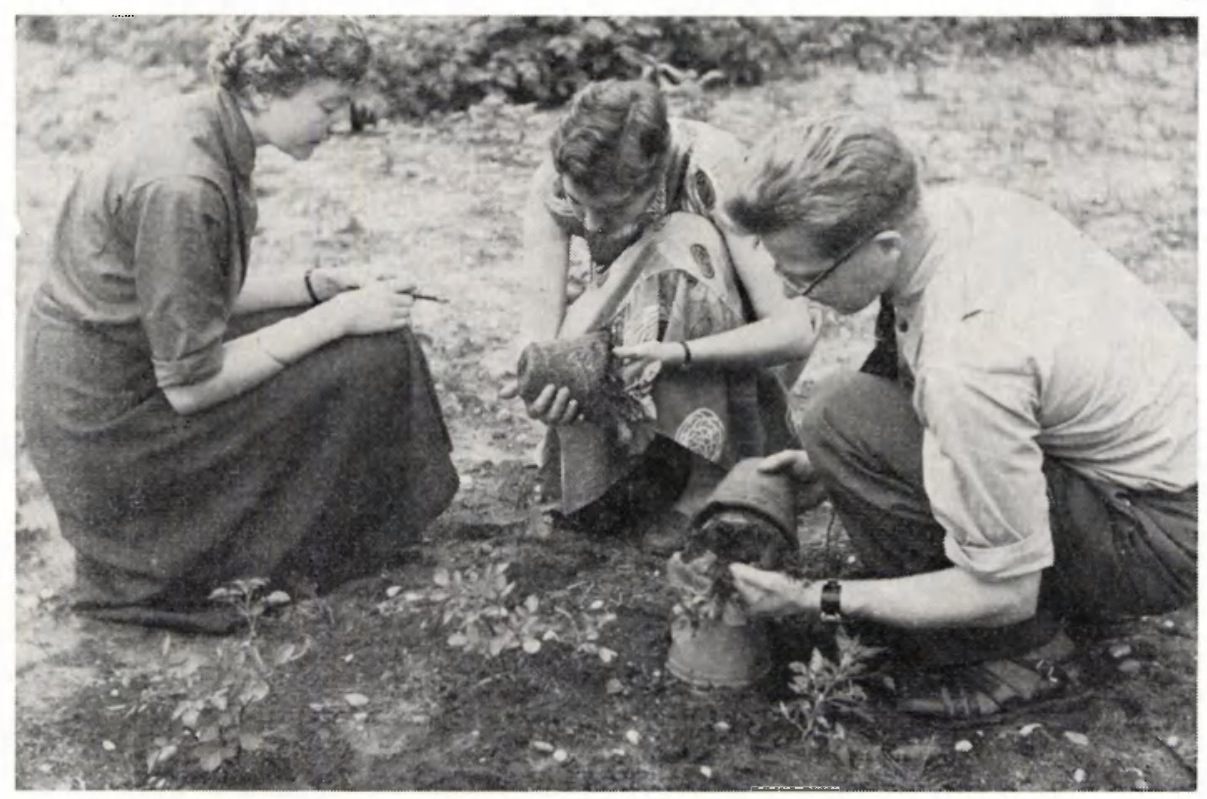

Fig. 1 Testing fon hesistance.

the pots are dug into the soil or into peat dust as far as the brim in order to prevent excessive evaporation.

If tubers are available for testing experiments, they are directly planted in infested soil in the above-mentioned pots of $13-17 \mathrm{~cm}$ diameter.

When very precious material is involved, the tubers are first induced to produce roots in little pots filled with healthy soil and later on transplanted into large pots which are filled with infested soil.

The examination for resistance can begin about eight weeks after transplanting in infested soil. After this period cysts, if any, are clearly visible; they are yellow to orange in colour and are clearly conspicuous against the roots and soil particles. For assessing the plants are removed from the pots and the roots visible at the surface of the rootball are inspected for the presence of cysts (Fig. I). If desired the examination can be repeated later, as the potball can be put back again into the pot with little damage to the plant.

Although this method is a "superficial" one - in as far as only part of the root system is inspected - yet for breeding purposes it has proved of great value since large numbers of seedlings can be tested in a comparatively short 
time. And the handling of large numbers is important since the resistance occurs but sporadically in nature.

At Wageningen thousands of plants have been tested in the course of years. Resistance was found in:

a Five clones derived from the Commonwealth Potato Collection (CPC), all of them belonging to the species S. tuberosum subsp. andigena. An indication of the occurrence of this resistance was first found by Eulenby (5); the most resistant number is CPC 1673.

b Some clones of S. vernei and S. sucrense $(4,9)$.

c Some clones of $S$. macolae and S. famatinae. Both these species are diploid.

d Five andigena-numbers of the collection of South American potatoes (10). at Wageningen. This collection comprises some 900 clones.

It stands to reason that most attention is paid to the resistant andigenamaterial as this material belongs to the same species (S. tuberosum) as our cultivated varieties and consequently are easy to cross with.

In the Netherlands so far the line CPC 1673 has been used almost exclusively. The following details are related to this line or to its offspring.

3 The inheritance of THE REsistance

To design a justifiable breeding programme, it is necessary first to know the mode of inheritance of the resistance. For this purpose crosses were made between different resistant clones of $S$. tuberosum subsp. andigena and between plants of this species and susceptible commercial varieties. The seedlings derived from these crossings were raised and then tested according to the above-mentioned method. It appeared that these seedlings were either entirely free from cysts or attacked just as heavily as the susceptible control-plants. Transitional stages did not occur. On some plants sometimes a small number of cysts (1-5) were found; from special experiments it appeared that these plants had to be classified as resistant ones.

The segregations observed, in resistant and susceptible, could be adequately explained by assuming the resistance to be due to one dominant gene $\mathbf{H}$, inherited in a tetraploid manner.

Resistant plants can then be represented by the following genetical formulae:

$$
\begin{gathered}
\text { H h h h : simplex, } \\
\text { H H h } \text { : duplex, } \\
\text { H H H : triplex, } \\
\text { H H H H : quadruplex; } \\
\text { a susceptible plant by h h h (nulliplex). }
\end{gathered}
$$

There appeared to be no difference in the degree of resistance between simplex and duplex seedlings. However, there are great differences in the numbers of resistant offspring of these categories when crossed with a susceptible partner. A simplex resistant plant gives $50 \%$ resistant offspring, a duplex plant about $83 \%$, triplex and quadruplex plants $100 \%$.

Some examples of such segregations in resistant and susceptible are tabulated below (Table 1). 
Table 1 Results of testing seedlings of the first backcross-generation.

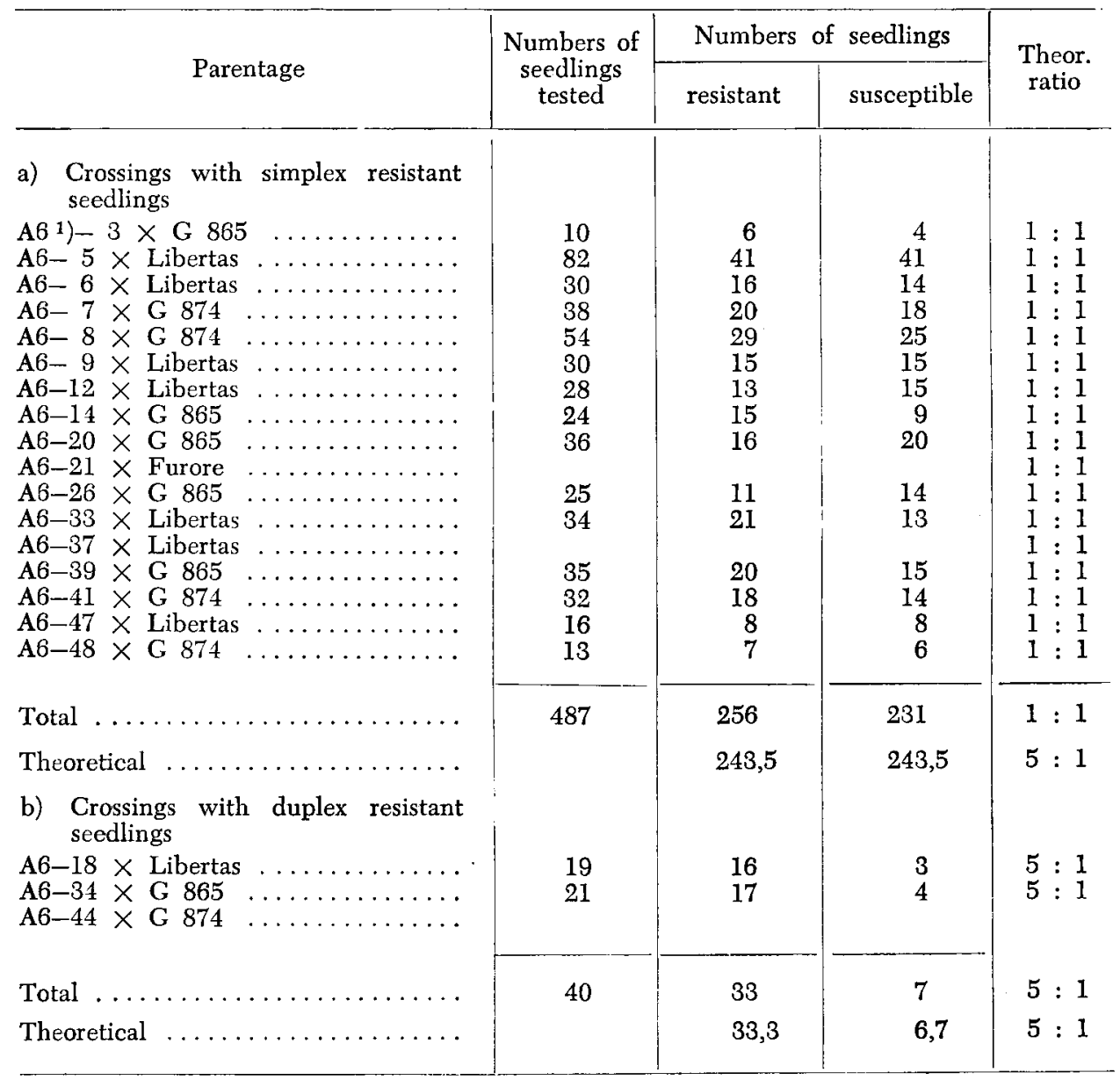

1) A6 : Record $\times 1673-1$.

On backcrossing of resistant $F_{1}$-plants with susceptible parents the resistance is maintained to the same degree and this fact is of great importance for potato breeding.

If plants derived from crosses between the resistant clone CPC 1673 and susceptible tuberosum-varieties are tested in the way described above, plants will occur with very few cysts apart from the ones which are heavily attacked and the ones which are not at all affected. Genetical examination proved that such plants possess the gene $H$. Close observations have taught that they possess a somewhat lower degree of resistance than the plants which on testing appear to be entirely free from cysts. These slight differences have a genetical basis.

4 Breeding COMmercial Potatoes For Resistance to Heterodera rostochiensis W.

From the investigations described above it follows that in breeding potatoes for eelworm resistance no great difficulties are to be expected. The method of repeated backcrossing was used. In this procedure the gene $\mathrm{H}$ derived from 
a plant with little cultural value (at least in this country) is transferred into the genom of our good potato varieties.

On account of the favourable way of inheritance it is not difficult to raise large numbers of resistant seedlings. However, selecting from this material seedlings with favourable qualities (e.g. short stolons, good yield, convenient size, good starch-quality etc.) is a difficult and time-consuming work, the technical details of which will not be treated in this article. It can be stated that very promising seedlings were found in the first backcross generation already.

\section{The nature of the resistance}

The roots of the resistant plants as well as those of the susceptible ones produce the "hatching factor", a substance that induces the larvae to leave the cyst and to penetrate into the roots of the plant. It appeared that the concentration of this root-diffusate of some resistant andigena $\times$ tuberosumseedlings was of the same order as that of the susceptible variety Eigenheimer. The number of larvae invading the roots of resistant plants is certainly not lower than that penetrating the roots of susceptible plants. It is difficult to draw an exact comparison as the numbers of invading larvae are also influenced by the size and structure of the root system. Resistant and susceptible seedlings of the same cross will always show inheritable differences in this respect.

In resistant roots, however, the development of the larvae and especially of the female ones is inhibited. (Fig. 2).

numbers of larvae

per $5 \mathrm{~g}$ root weight

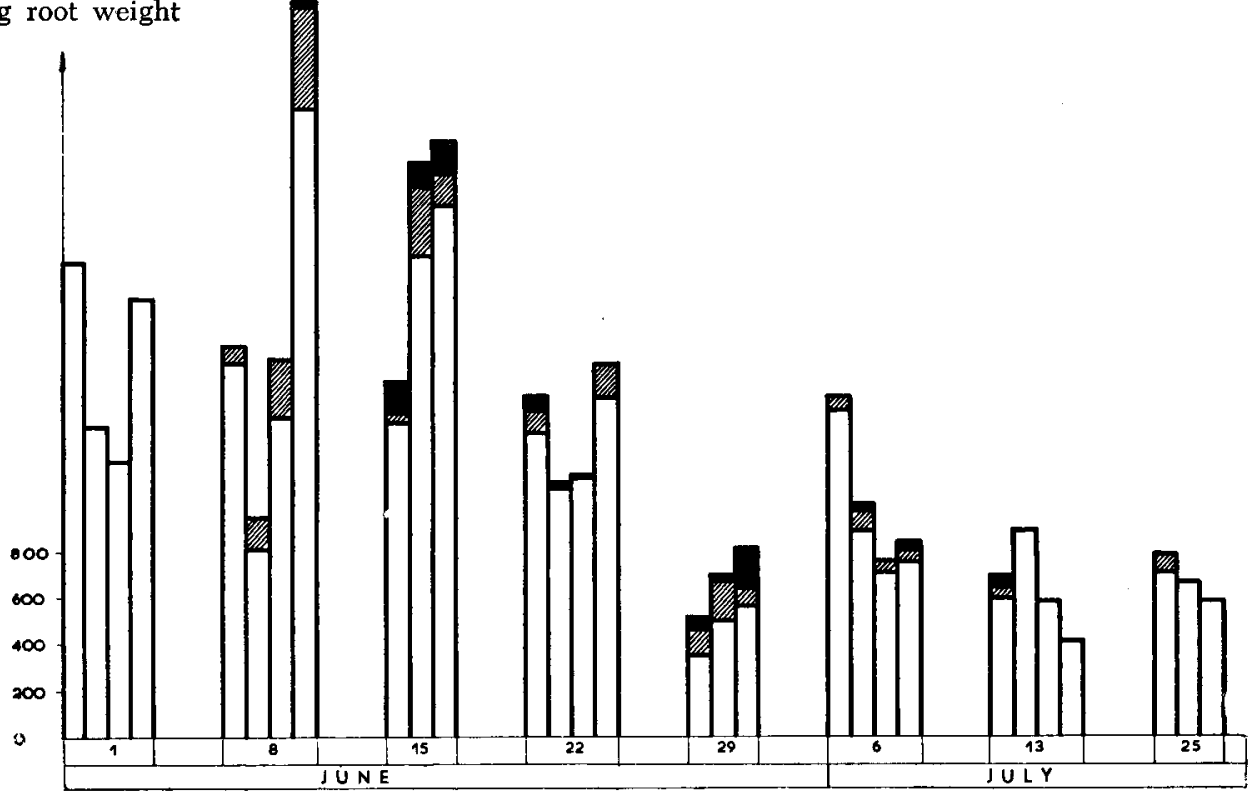

Fig. 2 Numbers of larvae that penetrated into the roots of a mesistant andigena $\times$ tuberosum CLONE AND THEIR DEVELOPMENT IN THE COURSE OF TIME.

$\square$ second stage larvae

third stage larvae

- higher stages of male larvae 
Females reach maturity only sporadically; mature males are fairly frequently observed. This difference in development between the sexes in roots of resistant plants can possibly be explained in the following way. After being about ten days in the roots the larvae start moulting. After this period the males are still in their old skin. It is assumed that they do not take up food any more. The females contrarily moult repeatedly, but their mouth and anus continue to stay in such a position that it is likely that they go on feeding. It is therefore accepted that the females continue to take up food and by that they are much more subjected to unfavourable conditions in the interior of the resistant roots. Nothing is known about the growth-inhibiting factor; may be there is a substance detrimental to the development of the larvae; but there is also a possibility that one or more substances are lacking that are necessary for the development of the larvae.

In order to learn more about the nature of the resistance, resistant plants were grafted on to susceptible ones and the other way round. However, no influence of the scion on the rootstock could be established as concerns the degree of resistance or susceptibility, so that this experiment gave no clearer solution to the problem.

On close examination of the root system of resistant plants mostly a few cysts are found, to be true. But contrary to expectation these cysts do not contain an abnormally small number of eggs. Possibly these females have developed on places of the roots where the physiological conditions determining the resistance are absent or less manifest. One could even suggest that there are islands of tissue in which by a somatic mutation the gene $\mathrm{H}$ has changed into $h$.

From field trials it appeared that the resistant potato varieties are greatly damaged by the invasion of large numbers of larvae into the roots. (Fig. 3). It is highly probable that resistant varieties are equally sensitive to potato sickness as susceptible ones and thus on heavily infested soils are equally affected as susceptible varieties. The great advantage of growing resistant varieties is that they do not enlarge the population of the potato root eelworm. On the contrary, it appeared that the growing of resistant varieties lowered the degree of infestation of the soil (6). For these resistant potatoes exert a nematocidal influence by secreting a hatching substance and by inhibiting the development of the invaded larvae. The reduction of the larvae-population in the soil by growing a resistant potato variety is greater than when immune crops are grown. The reduction which then occurs is to be ascribed to the hatching influence of the moisture in the soil (2).

\section{Biological RaCES OF THE POTATO ROOT EELWORM}

At first no indications were found for the existence of biological races of Heterodera rostochiensis which would be able to multiply in the resistant material derived from CPC 1673. The possibility, however, that such varieties will be found in the future has been soundly accounted for.

In 1956, DR. Toxopeus of the Institute of Agricultural Plant Breeding, made a tour to Peru and Bolivia in order to collect new material (11). One of the main objects was to broaden the basis of the breeding work for Heteroderaresistance which in the Netherlands is exclusively based on the offspring of one resistant clone. 


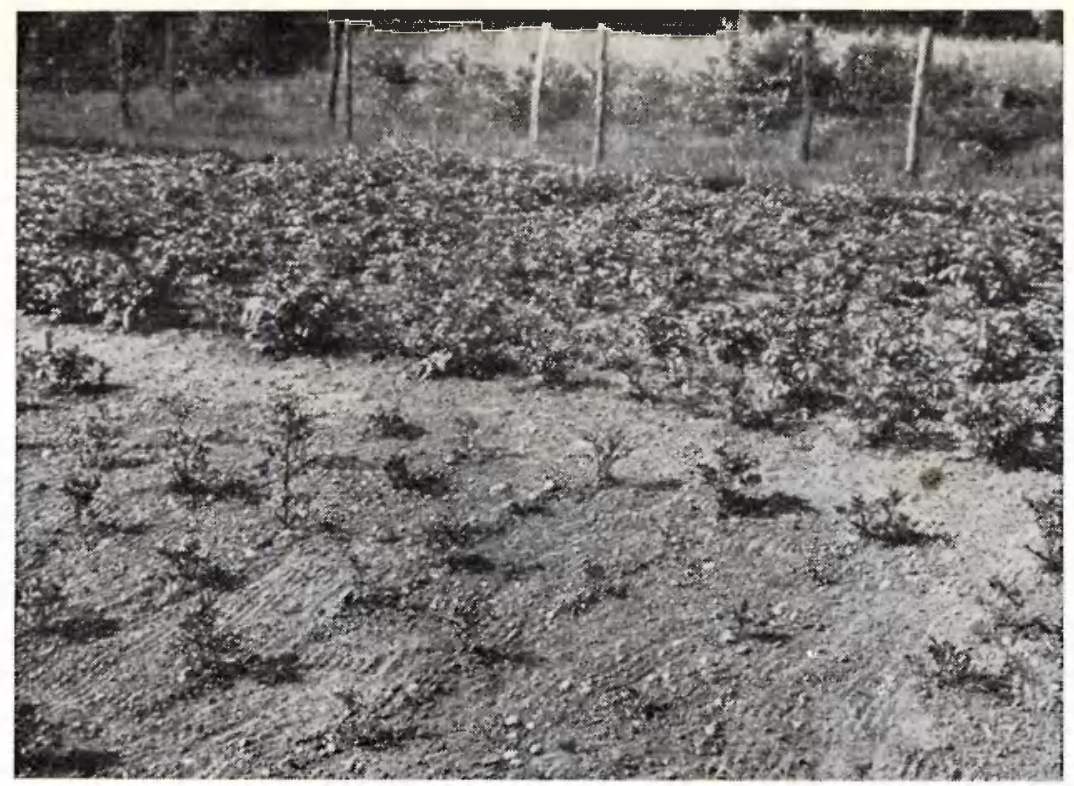

Fic. 3 Photograph showng the sensitivity of the resistant Material. Iv the foreGROUND PLANTS ON A PLOT IN WHICH SOME 40.000 LIVING EGGS PER $200 \mathrm{~g}$ AIRDRY SOIL ARE FOUND; IN THE BACKGROUND THE SAME MATERIAL ON A PLOT CONTAINING SOME 5000 LIVING EGGS PER 200 g AIRDRY SOIL.

The first indication of the existence of more aggressive forms of the parasite was found by VAN DER LAAN and the present writer, when they grew resistant plants in pots which were inoculated with cysts derived from Peru (8). On the roots of these plants considerably more cysts developed than on the roots of the same material grown in pots infected with equal numbers of cysts that were isolated from soil of an infested plot in the vicinity of Wageningen.

That these different forms were found in Peru, of all places, is not surprising. For the centre of origin of the potato lies in the North of SouthAmerica and Peru forms part of it. The hypothesis is obvious that the potato root eelworm originated in the same region. The genetical variability of the parasite must be greater there than in Western Europe. The fact that the potato root eelworm occurs almost everywhere in Peru supports this hypothesis and it seems that its genetical variability is indeed wider there $(1,11)$.

A more reliable indication of this variability was gained in 1956. In 1955 a number of resistant clones, derived from CPC 1673, were sent from Wageningen to Peru. They were tested for resistance by Ir. S. Simon of the Estacion Experimental Agricole de la Molina. It appeared that all the seedlings which we had found to be resistant were heavily affected in soil derived from Maco Farm (Prov. of Tarma). From the report of Ir. Simon it can be concluded that the roots of these seedlings were as heavily crowded with cysts as those of our susceptible varieties when grown in highly infested soil of Western Europe (10).

In the meantime similar aggressive forms of the parasite were also found in England and Scotland $(3,7)$. Although the experiments have not been run long enough to draw decisive conclusions the English workers assume the 
occurrence of biological races which are equally aggressive in regard to the resistant varieties as the "common" biological race with respect to our susceptible commercial varieties. Besides there seem to be races that are less aggressive.

It is estimated that the area of infested land on which resistant varieties derived from CPC 1673 and other resistant andigena-varieties can be grown effectively should be reduced by 10 per cent on account of the possible occurrence of these biological races. A favourable feature is that the potato root eelworm is a soil-parasite and that it spreads only very slowly.

It is unknown how matters stand in the Netherlands as concerns the occurrence of the aggressive races ${ }^{3}$ ). The problem is studied and investigated extensively. The existence of aggressive types of the eelworm should be certainly taken into account.

In conclusion it can be said that the problem of potato sickness has not been solved completely by the preliminary successful results of the breeding work. It is reasonable that in the near future a thorough search will be made for initial material that will be also resistant to the new races.

\section{REFERENCES}

1 Baxan De Segura, C. : More about the golden nematode in Peru. The Plant Disease Reporter 37 (1953) 326.

2 BrjLoo, J. D. : Population decrease of Heterodera rostochiensis after DD treatment of the soil. Nematologica 1 (1956) 20-30.

3 DunnetT, J. M. : Variation in pathogenicity of the potato root eelworm (Heterodera rostochiensis WoLL.) and its significance in potato breeding. Euphytica 6 (1957) $77-89$.

4 Ellensy, C. : Resistance to the potato-root eelworm. Nature 162 (1948) 704.

5 - - : Resistance to the potato root eelworm Heterodera rostochiensis Wollenweber. Nature 170 (1952) 1016.

6 Huijsman, C. A. : Veredeling van de aardappel op resistentie tegen Heterodera rostochiensis Wollenweber. Publication No. 14 of the Foundation for Agr. Plant Breeding, Wageningen, The Netherlands (1957).

7 Jones, F. W. G. : Resistance-breaking biotypes of the potato root eelworm (Heterodera rostochiensis WOLL.). Nematologica 2 (1957) 185-192.

8 LAAN, P. A. vaN DER and C. A. HuIJsman : Een eerste aanwijzing voor het bestaan van biotypen van het aardappelcystenaaltje, welke zich sterk kunnen vermeerderen in resistente nakomelingen van Solanum tuberosum subsp. andigena. Tiidschrift over Planteziekten (1957), in the press.

9 MaI, W. F. and L. C. Peterson : Resistance of S. ballsii and S. sucrense to the golden nematode Heterodera rostochiensis Wollenweber. Science 116 (1952) 224-225.

10 Quevedo, A., J. E. Simon and H. J. Toxopeus : Estudios de resistancia a la anguilula dorada de la papa. Inf. Estac. agric. La Molina 347 (1956) 10-15.

11 Toxopeus, H. J. : Collecting cultivated potatoes in South America for potato breeding. Euphytica 5 (1956) 97-100.

12 Wille, J. E. and C. BazAn de Segura: Anguilula dorada, Heterodera rostochiensis una plaga del cultivo de las papas, recien descubierta en el Peru. Ministeria de Agricultura (Peru) Boletin 48 (1952) 1-47.

3) From investigations carried out in the meantime, it has appeared that in the Netherlands, too, aggressive races of the potato root eelworm, which can multiply strongly in resistant material derived from CPC 1673, occur in some places. 